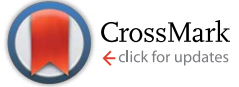

Cite this: RSC Adv., 2015, 5, 107482

Received 20th October 2015 Accepted 11th December 2015

DOI: $10.1039 / \mathrm{c} 5 \mathrm{ra} 21962 \mathrm{k}$

www.rsc.org/advances

\section{Investigation of different aqueous electrolytes on the electrochemical performance of activated carbon-based supercapacitors $\uparrow$}

\author{
F. Barzegar, ${ }^{\text {a D. Y. Momodu, }}{ }^{\text {a }}$ O. O. Fashedemi, ${ }^{\text {b A. Bello, }}{ }^{\text {a }}$ J. K. Dangbegnon ${ }^{a}$ \\ and N. Manyala*a
}

In this study, porous activated carbons (AC) were synthesized by an environmentally friendly technique involving chemical activation and carbonization, with an in-depth experimental study carried out to understand the electrochemical behaviour in different aqueous electrolytes $\left(\mathrm{KOH}, \mathrm{LiCl}\right.$, and $\left.\mathrm{Na}_{2} \mathrm{SO}_{4}\right)$. The electrochemical performance of the AC electrode was evaluated by different techniques such as cyclic voltammetry, galvanostatic charge/discharge and impedance spectroscopy. The results obtained demonstrate that the $A C$ materials in different electrolytes exhibit unique double layer properties. In particular, the $\mathrm{AC}$ electrode tested in $6 \mathrm{M} \mathrm{KOH}$ showed the best electrochemical performance in terms of specific capacitance and efficiency. A specific capacitance of $129 \mathrm{~F} \mathrm{~g}^{-1}$ was obtained at $0.5 \mathrm{~A} \mathrm{~g}^{-1}$ with a corresponding solution resistance of $0.66 \Omega$ in an operating voltage window of $0.8 \mathrm{~V}$, with an efficiency of $\sim 100 \%$ at different current densities.

\section{Introduction}

Supercapacitors (SCs) which are also referred to as electrochemical capacitors (ECs) have been extensively studied recently due to their unique capabilities for use in high power storage applications. This is due to their characteristic higher energy density as compared to conventional capacitors and much higher power densities than batteries presently in use. ${ }^{1-3}$ The mechanism of storage in supercapacitors can be used to broadly classify SCs into two groups namely; the electric double layer capacitors (EDLCs) and faradaic or pseudocapacitors. ${ }^{4}$ The energy storage mechanism in EDLCs depends on the efficient electrostatic accumulation of charges at the interface between electrode and electrolyte. ${ }^{5}$ In this charge storage process, there is no transfer of charges. On the other hand, energy storage in pseudocapacitors is governed by fast redox processes involving the transfer of charges between the electrode/electrolyte interfaces. ${ }^{6}$

The most common materials used for EDLCs are the carbonbased materials ${ }^{7-9}$ due to their low cost, controllable porous nature with a corresponding high specific surface area (SSA), suitable conductivity, chemical stability, adjustable structural properties and excellent electrochemical behavior which makes

${ }^{a}$ Department of Physics, Institute of Applied Materials, SARCHI Chair in Carbon Technology and Materials, University of Pretoria, Pretoria 0028, South Africa. E-mail: ncholu.manyala@up.ac.za; Fax: +27 12420 2516; Tel: +27 124203549

${ }^{b}$ Department of Chemistry, University of Pretoria, Pretoria 0002, South Africa

$\uparrow$ Electronic supplementary information (ESI) available: Electrochemical characterization at 0.5 potential window. See DOI: $10.1039 / \mathrm{c} 5 \mathrm{ra} 21962 \mathrm{k}$ them ideal for use in different advanced applications. ${ }^{\mathbf{8 , 1 0 - 1 2}}$ Such applications include; hybrid vehicles, regenerative braking systems, memory back-up systems in electronic devices, storage components in combination with batteries to enhance battery life..$^{13,14}$

Numerous studies ${ }^{5,12,14-17}$ have been carried out in order to fully understand the influence of electrolyte on the performance of carbon-based SCs. Activated porous carbons derived from chemical activation of polymer hydrogels ${ }^{\mathbf{1 8}}$ have particularly received growing interest from researchers worldwide due to their facile preparation method involved in obtaining the final products with the relatively high specific surface area. Since the capacitance in EDLCs largely depends on charge accumulation and adsorption at the electrode/electrolyte interface, the specific capacitance of carbon electrodes is generally influenced by changes in its specific surface area. ${ }^{\mathbf{1 9}}$ Although it is well known that a relatively high SSA carbon-based material with the abundant porous network is ideal for enhancing the performance of EDLC electrodes, there is still no clear-cut relationship between the capacitance and SSA. ${ }^{2021}$ It has however been established that the pore structure governs the energy storage and power delivery capability of the material. ${ }^{21}$

The availability of adequate mesopores and micropores within the porous morphology provides an avenue for sufficient movement of ions in the electrolyte. These result from contribution from the volume of active micropores $(<2 \mathrm{~nm}$ in size) serve as the ion traps for energy storage, while mesopores (2-50 $\mathrm{nm}$ ) act as the ion transport pathways for power delivery, ${ }^{22,23}$ and the macropores (>50 $\mathrm{nm}$ in size) playing the role of an ion buffering reservoir. ${ }^{23}$ Furthermore, the pore size distribution in 
relation to the size of the electrolyte ions significantly affects the electrochemical properties of the EDLC carbon electrodes. ${ }^{24}$

Organic and ionic electrolytes are commonly used for commercial applications involving carbon-based materials due to their wide operating voltages ${ }^{25,26}$ which improves the overall energy density. This is due to the direct relationship between the energy density of the SC with respect to the operating voltage. However, organic and ionic liquids are plagued with some demerits which include high cost, low conductivity (large internal resistance), generally complicated handling procedures involved, high flammability and electrolyte leakage. ${ }^{27}$ In contrast, aqueous electrolytes have lower cost, environmentally friendly nature, facile preparation methods and operating stability, high ionic conductivity and proton transport which is necessary for obtaining lower internal resistance. ${ }^{28}$ It is worthy to state that even though aqueous electrolytes are characterized with a limited operating voltage in comparison with organic electrolytes, the ions present in the former are still capable of much faster transport rates in relation to the latter. ${ }^{10}$ Thus, efforts are geared towards extending the operating voltage window of these electrolytes in order to improve the overall working potential and energy density of the SC device.

A major step to achieving this is by studying the effect of different aqueous electrolytes on the electrochemical behavior of activated porous carbons in order to fully understand the adaptability of these porous networks with the associated electrolyte. Unfortunately, very few reports presently exist in which a detailed study have been carried out regarding this area. Zhu et $a .^{29}$ investigated the effect of various electrolyte cations $\left(\mathrm{Li}^{+}, \mathrm{Na}^{+}, \mathrm{K}^{+}, \mathrm{H}^{+}\right)$on the electrochemical performance of polypyrrole/RGO based supercapacitors. They report that $\mathrm{H}^{+}$ cation has a significantly improved result which is due to ionic conductivity, efficient ion/charge diffusion/exchange and relaxation time of the $3 \mathrm{M} \mathrm{HCl}$ compare to the rest of electrolyte that they investigated. Eliad et al. ${ }^{30}$ investigated the estimating effective ion size in electrolytic solutions for porous carbon electrodes. They report that the capacitance of the material will be controlled by the relationship between the average pore size of material and the effective size of electrolyte ion.

This study therefore investigates and elucidates the effect of different aqueous electrolytes on highly conductive activated porous carbons obtained from chemically activating graphenedoped polymer gels. The results obtained demonstrate a complete analysis of the electrochemical performance of carbon-based supercapacitors tested in $\mathrm{KOH}, \mathrm{LiCl}$ and $\mathrm{Na}_{2} \mathrm{SO}_{4}$ electrolytes. The choice of these aqueous electrolytes is based on their unique properties which include the crystal radius, ionic mobility, Gibbs energy amongst other properties mentioned earlier. The results show the potential for adopting activated porous carbons as suitable material for SC electrodes.

\section{Experimental}

\section{Preparation of activated carbon electrode}

Activated carbon (AC) was first prepared by the process reported in our previous work. ${ }^{31}$ The electrode was prepared by mixing the active material (AC) and polyvinylidene fluoride (PVDF) as a binder with a weight ratio of $9: 1$, homogenized and dispersed in $N$-methylpyrrolidone (NMP) solution, and the slurry was then uniformly pasted on a nickel foam current collector and dried at $60{ }^{\circ} \mathrm{C}$ in an oven for 8 hours to ensure complete evaporation of the NMP. The three electrode measurements were performed with $\mathrm{AC}$ as the working electrode, $\mathrm{Ag} / \mathrm{AgCl}(3 \mathrm{M} \mathrm{KCl})$ serving as the reference and glassy carbon plate as the counter electrode in different electrolyte solutions of 6.0 M KOH, 1.0 $\mathrm{M} \mathrm{Na}_{2} \mathrm{SO}_{4}$ and 6.0 $\mathrm{M} \mathrm{LiCl}$ for evaluation of the electrochemical behavior.

\section{Characterization}

The sample was characterized using powder X-ray diffraction (XRD). An XPERT-PRO diffractometer (PANalytical BV, Netherlands) with theta/theta geometry, operating a cobalt tube at 35 $\mathrm{kV}$ and $50 \mathrm{~mA}$ was used to study the crystal structure of the AC material. Nitrogen adsorption-desorption isotherms were measured at $-196{ }^{\circ} \mathrm{C}$ using a Micromeritics TriStar II 3020 (version 2.00) analyzer. The sample was degassed at $180^{\circ} \mathrm{C}$ for more than $12 \mathrm{~h}$ under high vacuum condition before measurements were made. The surface area was calculated by the Brunauer-Emmett-Teller (BET) method from the adsorption desorption isotherm. The morphology of the AC was obtained on a Zeiss Ultra Plus 55 field emission scanning electron microscope (FE-SEM) operated at an accelerating voltage of 2.0 $\mathrm{kV}$. Transmission electron microscopy (TEM) was carried out with a JEOL JEM-2100F microscope operated at $200 \mathrm{kV}$ accelerating voltage. All electrochemical measurements were carried out using a Bio-logic VMP-300 potentiostat. These measurements included cyclic voltammetry (CV), chronopotentiometry (CP) and electrochemical impedance spectroscopy (EIS). The CV tests were carried out at different scan rates ranging from 5 to $100 \mathrm{mV} \mathrm{s}^{-1}$, and the electrochemical impedance spectroscopy (EIS) measurements were conducted in the frequency range from 0.1 to $100 \mathrm{kHz}$ with an open circuit potential $(\sim 0 \mathrm{~V})$.

\section{Results and discussions}

Fig. 1(a) represents the XRD patterns of AC powder. The wavelength used for the XRD analysis was $\mathrm{Cu}-\mathrm{K}_{\alpha}, 1.5405 \AA$ A. The XRD pattern of the PAC sample is made of two distinctive features: broad peaks which are always overlapping with sharp ones. The broad diffraction peaks could be arising from the amorphous nature of the activated carbon with some degree of graphitization responsible to the presence of sharp and intense graphitic diffraction pattern.

It is noted that all the XRD peaks are identified to graphite peaks (COD: 96-900-8570) which crystallize in the orthorhombic system with space group $P 63 m c(186)$, lattice parameters $a=2.4560 \AA$ and $c=6.6960 \AA$ A. Fig. 1(b) represents the BET results of AC material. The nitrogen adsorption and desorption isotherm shows type II characteristics with $\mathrm{H} 4$ hysteresis loop corresponding to a complex mixture of micro and mesoporous structure for the AC sample. The corresponding specific surface area of $\mathrm{AC}$ is $1063 \mathrm{~m}^{2} \mathrm{~g}^{-1}$. The $\mathrm{BJH}$ desorption average pore diameter $(4 \mathrm{~V} / \mathrm{A})$ from Table 1 for $\mathrm{AC}$ is $2.79 \mathrm{~nm}$, suggesting that the pore diameter of our material is bigger than all ions for all 

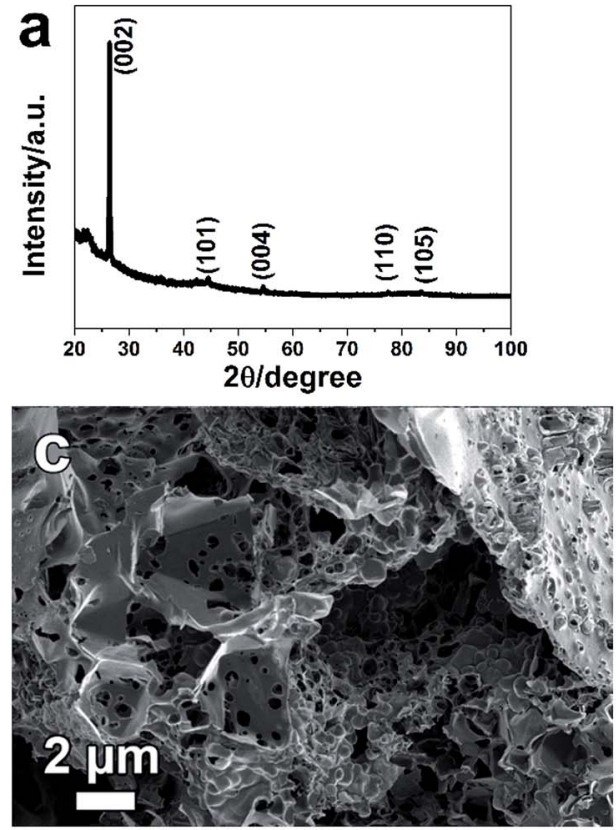

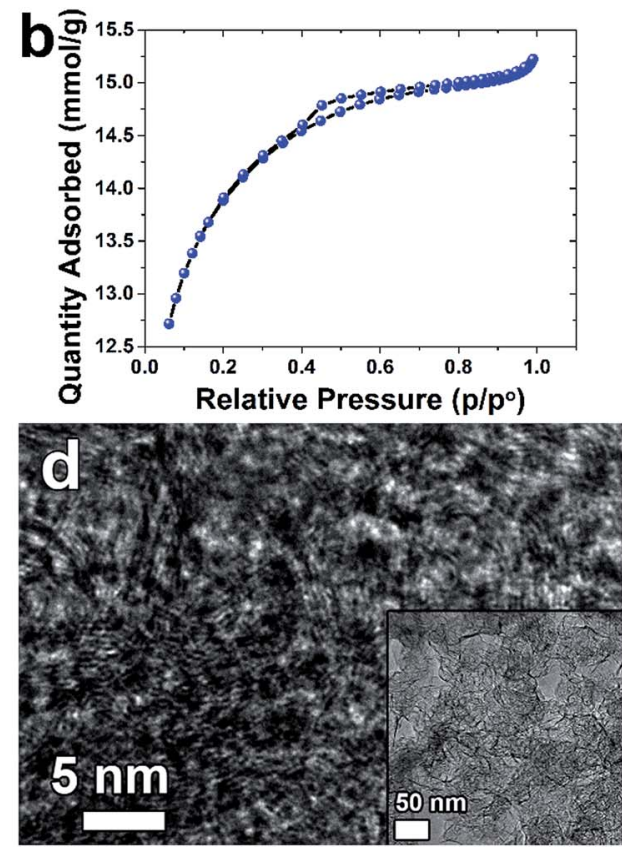

Fig. 1 (a) the X-ray diffraction, (b) $\mathrm{N}_{2}$ adsorption-desorption isotherm, (c) SEM image, and (d) TEM image of AC.

the electrolytes that were used as observed from Table 2. Fig. 1(c) represents the SEM image of AC. It clearly shows mesoporous structure resulting from the $\mathrm{KOH}$ activation and carbonization process. This type of structure could provide ion path way for efficient transport during electrochemical measurement and hence suitable for fast ion transport for high performance supercapacitors. The TEM image (Fig. 1(d)) verifies that the pores are homogeneously and uniformly distributed throughout the structure of the sample. Partially crystallized carbon material is suggested by the appearance of fringes which could be due to the separation of graphite sheet. The measured interlayer distances are in the range of $0.35-0.38$ $\mathrm{nm}$, a little larger than the $d$-spacing of (002) crystal plane $(0.335 \mathrm{~nm})$ of bulk graphite due to slight expansion and distortion. ${ }^{32}$

The electrochemical behavior of the carbon nanosheets was evaluated in a three-electrode system with various aqueous electrolytes. The cyclic voltammetry (CV) comparison profiles measured at a scan rate of $5 \mathrm{mV} \mathrm{s}^{-1}$ are shown in Fig. 2(a). The $\mathrm{CV}$ profiles of the carbon material in different electrolytes show a fairly rectangular shape indicating EDLC response. The differences observed in current response and CV behaviors of

Table 1 Surface area, micropore and cumulative volume and pore size of $A C$

\begin{tabular}{llll}
\hline $\begin{array}{l}\text { Surface area } \\
\left(\mathrm{m}^{2} \mathrm{~g}^{-1}\right)\end{array}$ & $\begin{array}{l}\text { Micropore } \\
\text { volume }^{a}\left(\mathrm{~cm}^{3} \mathrm{~g}^{-1}\right)\end{array}$ & $\begin{array}{l}\text { Cumulative } \\
\text { volume }^{b}\left(\mathrm{~cm}^{3} \mathrm{~g}^{-1}\right)\end{array}$ & $\begin{array}{l}\text { Pore } \\
\text { diameter }\end{array}$ \\
\hline 1063 & 0.33 & 0.13 & 2.79
\end{tabular}

${ }^{a} t$-Plot micropore volume. ${ }^{b} \mathrm{BJH}$ desorption cumulative volume of pores between $1.7000 \mathrm{~nm}$ and $300.0000 \mathrm{~nm}$ diameter. ${ }^{c} \mathrm{BJH}$ desorption average pore diameter $(4 \mathrm{~V} / \mathrm{A})$.
AC in different electrolytes come from different physical properties of the ions from these different electrolytes. Some of these properties include the ionic radius, radius of ionic hydration sphere, molar conductivity and ionic mobility.

Table 2 represents the ionic radius, radius of water of hydration, free energy formation of water of hydration and conductivity of $\mathrm{Li}, \mathrm{Na}, \mathrm{K}$ ions. Generally, alkali metal ions are strongly solvated in water, therefore, the radius of hydration sphere decreases in the following order: $\mathrm{Li}^{+}>\mathrm{Na}^{+}>\mathrm{K}^{+}{ }^{14}$ As seen in the table $\mathrm{Li}^{+}$is a highly solvated cation with a radius hydration sphere of $3.82 \AA$, while the radii hydration sphere values of the other two cations are somewhat in the same range, though lower. As the bulk electrolyte is a dynamic system, the number of water molecules around alkali metal ions cannot be strictly defined. Therefore, the main factors in determining super capacitive performance using different electrolytes have to be those of mobility and conductivity of the ions. From Table $2, \mathrm{~K}^{+}$ions have the highest molar conductivity with a value of $73.5 \mathrm{~cm}^{2} \Omega^{-1} \mathrm{~mol}^{-1}$; a value which is almost two folds as compared to that of $\mathrm{Li}^{+}$ion, while $\mathrm{Na}^{+}$ion has a value of $50.1 \mathrm{~cm}^{2} \Omega^{-1} \mathrm{~mol}^{-1}$, thus making $\mathrm{Li}^{+}$the cation with the lowest conductivity. Consequently, $\mathrm{K}^{+}$ions being characterized by the highest mobility can easily migrate into the electrode/ electrolyte surface during charging and into the electrolyte bulk during discharging. The presence of the bigger $\mathrm{SO}_{4}{ }^{2-}$ anion will reduce the mobility of $\mathrm{Na}^{+}$cation thus making the electrochemical behavior of the capacitor in the $\mathrm{Na}_{2} \mathrm{SO}_{4}$ electrolyte less favorable. Thus capacitive performance may be reduced in $\mathrm{Na}_{2} \mathrm{SO}_{4}$ despite the lower molar conductivity of $\mathrm{Li}^{+}$ compared to that of $\mathrm{Na}^{+}$cation. The specific capacitance $\left(C_{\mathrm{S}}\right)$ can be calculated from $\mathrm{CV}$ curves according to the following equation: ${ }^{33}$ 
Table 2 Crystal radius, radius of hydration sphere, free energy of hydration, conductivity of alkali ions (in water solution at $25^{\circ} \mathrm{C}$ ) ${ }^{14,34-36}$

\begin{tabular}{llllll}
\hline Alkali ion & $\begin{array}{l}\text { Crystal radius } \\
(\AA)\end{array}$ & $\begin{array}{l}\text { Radius of hydration } \\
\text { sphere }(\AA)\end{array}$ & $\begin{array}{l}\text { Gibbs energy } \\
\left(\mathrm{kcal} \mathrm{mol}^{-1}\right)\end{array}$ & $\begin{array}{l}\text { Molar conductivity } \\
\left(\mathrm{cm}^{2} \Omega^{-1} \mathrm{~mol}^{-1}\right)\end{array}$ & $\begin{array}{l}\text { Ionic mobility } \\
\left(\mu 10^{-5} \mathrm{~cm}^{2} \mathrm{~s}^{-1} \mathrm{~V}^{-1}\right)\end{array}$ \\
\hline $\mathrm{Li}^{+}$ & 0.60 & 3.82 & 138.4 & 38.6 & - \\
$\mathrm{Na}^{+}$ & 0.95 & 3.58 & 162.3 & 50.1 & 7.2 \\
$\mathrm{~K}^{+}$ & 1.33 & 3.31 & 179.9 & 73.5 & - \\
$\mathrm{Cl}^{-}$ & 1.70 & 3.14 & - & 76.4 & 8.3 \\
$\mathrm{SO}_{4}{ }^{-}$ & - & 3.79 & - & 79.8 & 20.6 \\
$\mathrm{OH}^{-}$ & - & 3.00 & - & 198.0 &
\end{tabular}

$$
C_{\mathrm{S}}=\frac{\int I \mathrm{~d} U}{v m \Delta U}
$$

or $C_{\mathrm{S}}$ can be calculated from charge-discharge curves according to the equation: ${ }^{33}$

$$
C_{\mathrm{S}}=\frac{I \Delta t}{m \Delta U}
$$

where $I$ is the current, $\Delta U$ is the voltage difference, $v$ is the potential sweep rate $\left(\mathrm{mV} \mathrm{s}^{-1}\right), m$ is the mass of total electrode active materials and $\Delta t$ is the discharge time.

From Fig. 2(a) the CV curves for $\mathrm{AC}$ in $\mathrm{KOH}$ and $\mathrm{Na}_{2} \mathrm{SO}_{4}$ electrolytes show fairly rectangular shape while the $\mathrm{LiCl}$ demonstrate a highly resistive $\mathrm{CV}$ shape due to the molar conductivity which is less than that of $\mathrm{KOH}$ and $\mathrm{Na}_{2} \mathrm{SO}_{4}$ as shown in Table 1. The loading amount of active materials for electrochemical performance in $\mathrm{KOH}, \mathrm{LiCl}$ and $\mathrm{Na}_{2} \mathrm{SO}_{4}$ electrolytes are $3.8 \mathrm{mg}, 4.5 \mathrm{mg}$ and $5.5 \mathrm{mg}$ respectively.

Fig. 2(c) shows the specific capacitance as function of sweep rate. As expected from the molar conductivity of $\mathrm{K}^{+}, \mathrm{Na}^{+}$and $\mathrm{Li}^{+}$, the highest specific capacitive was obtained in $\mathrm{KOH}$ electrolyte followed by $\mathrm{Na}_{2} \mathrm{SO}_{4}$ and $\mathrm{LiCl}$ with the lowest molar conductivity. In other words, specific capacitance values of 123, 102 and $99 \mathrm{~F}$ $\mathrm{g}^{-1}$ were obtained at a sweep rate of $5 \mathrm{mV} \mathrm{s}^{-1}$ in $\mathrm{KOH}, \mathrm{Na}_{2} \mathrm{SO}_{4}$ and LiCl electrolytes respectively. At a higher sweep rate of 100 $\mathrm{mV} \mathrm{s}^{-1}$, the specific capacitance values remained at 79,55 and $54 \mathrm{~F} \mathrm{~g}^{-1}$ in the same order of electrolyte. This is in striking agreement with the molar conductivity of the cation molar conductivity, i.e., the higher the molar conductivity, the higher the specific capacitance. Also, the specific capacitance has direct relationship with hydration radius, as observed from Table 2, by reducing hydration radius, the specific capacitances are increased.

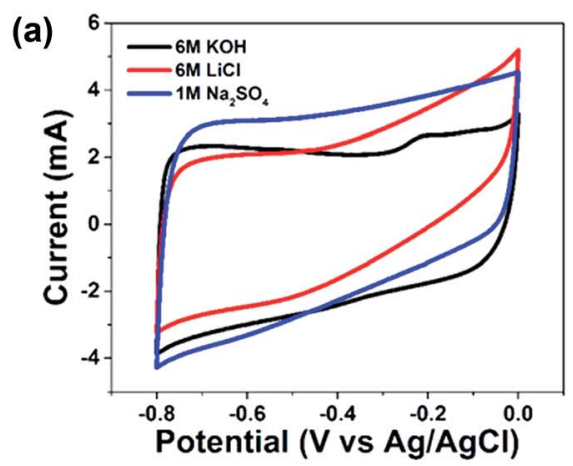

(c)

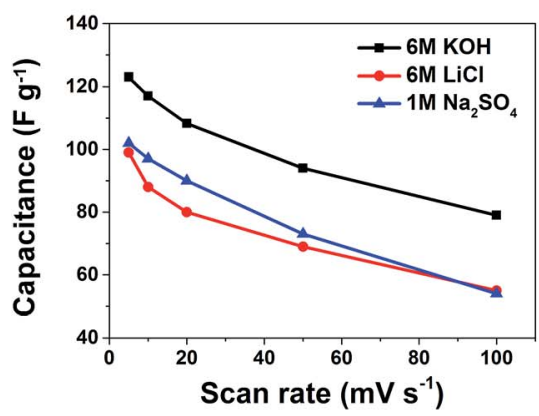

(b)

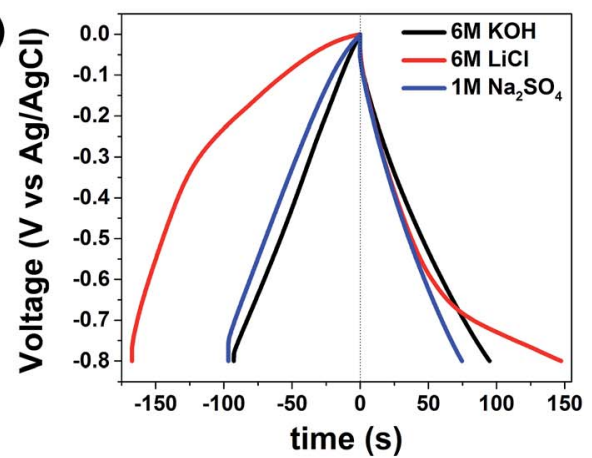

(d)

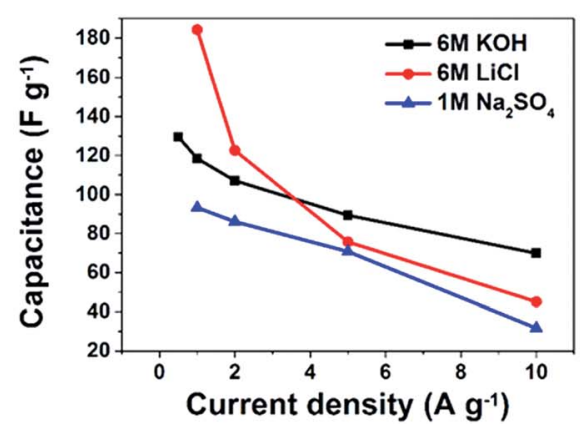

Fig. 2 (a) CV curves at scan rates of $5 \mathrm{mV} \mathrm{s}^{-1}$, (b) the galvanostatic charge/discharge curves at $1 \mathrm{~A} \mathrm{~g}^{-1}$, (c) the specific capacitance as function of the scan rate and (d) the specific capacitance as function of the current density at $0.8 \mathrm{~V}$ of AC different for different electrolytes as shown in the figures. 

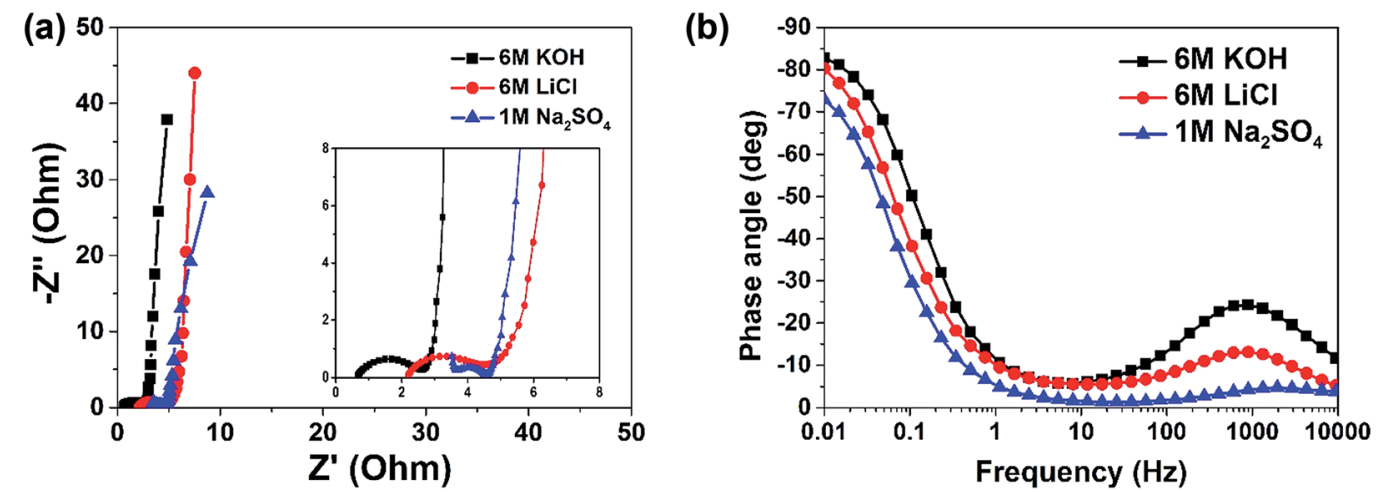

Fig. 3 (a) The Nyquist plots and (b) Bode phase angle plots in different electrolytes.

Furthermore, with increasing scan rates, the $\mathrm{KOH}$ reveals a stable capacitance when compared with the other two electrolytes; demonstrating a $65 \%$ capacitance retention at $100 \mathrm{mV}$ $\mathrm{s}^{-1}$ as observed from Fig. 2(c). This stability is tentatively attributed to the presence of surface carbonyl and oxygen functional groups in the AC that may lead to redox reactions with the $\mathrm{KOH}$ electrolyte thereby leading to increase and stability of the electrode material. ${ }^{14}$

Galvanostatic experiments were performed for more accurate capacitance assessment as the measurements from the $\mathrm{CV}$ are not sometimes reliable. They were measured at current densities ranging from 0.5 to $10 \mathrm{~A} \mathrm{~g}^{-1}$. A typical charge/ discharge curves in the three electrolytes is shown in Fig. 2(b). The highest capacitance value was obtained at $1 \mathrm{~A} \mathrm{~g}^{-1}$ in the LiCl electrolyte. However, as observed from Fig. 2(b) and (d), the AC material shows better symmetric triangular chargedischarge curves in $\mathrm{KOH}$ and $\mathrm{Na}_{2} \mathrm{SO}_{4}$ electrolyte. This suggests that the LiCl electrolyte was stretched beyond its capacity at 0.8 V. This was demonstrated by a non-symmetric chargedischarge curves thus resulting in higher capacitance values. For the purpose of clarification the experiment was repeated at a potential window of $0.5 \mathrm{~V}$ and the results are presented in Fig. S1 in the ESI. $\dagger$ From the CV shape of the LiCl presented in Fig. S1b and $d, \uparrow$ it is clearly seen that AC electrode gives a better EDLCs characteristics within a potential window of $0.5 \mathrm{Vvs} . \mathrm{Ag} /$ $\mathrm{AgCl}$. At a current density of $1 \mathrm{~A} \mathrm{~g}^{-1}$ and maximum potential window of $0.8 \mathrm{~V}$ the specific capacitance values are 118, 84 and $184 \mathrm{~F} \mathrm{~g} \mathrm{~g}^{-1}$ in $\mathrm{KOH}, \mathrm{Na}_{2} \mathrm{SO}_{4}$ and $\mathrm{LiCl}$ aqueous electrolyte respectively. The charge/discharge curves in $6 \mathrm{M} \mathrm{KOH}$ are almost perfect isosceles lines, with a charge/discharge efficiency of approximate $100 \%$. This shows the stability of the AC in the electrolyte. ${ }^{14}$ At higher current density of $10 \mathrm{~A} \mathrm{~g}^{-1}$ reduced capacitance values in all three solutions are expected due to the capacitance $v$ s. current load dependence. However, the same trend observed in the $\mathrm{CV}$ measurement at high scan rate is maintained and values obtained in the three electrolytes are 70 $\mathrm{F} \mathrm{g}^{-1}$ for $\mathrm{KOH}$, compared to $32 \mathrm{~F} \mathrm{~g}^{-1}$ and $45 \mathrm{~F} \mathrm{~g}^{-1}$ in $\mathrm{Na}_{2} \mathrm{SO}_{4}$ and $\mathrm{LiCl}$ respectively. From Tables S1, S2 and S3, $\uparrow$ it is very evident that the charge/discharge efficiency $(\eta(\%))$ of the electrode at different current densities, that of $6 \mathrm{M} \mathrm{KOH}$ electrolyte is higher than the other two electrolytes.
Fig. 3(a) shows Nyquist plots of AC in the different electrolytes obtained from the EIS experiments. Although all the three plots appear to have the nearly typical capacitive shape and vertical profile at lower frequencies with low diffusion resistance, the magnified image/spectra inset to Fig. 3(a) gives the differences in the solution resistance $\left(R_{\mathrm{S}}\right)$ values of $\mathrm{AC}$ in the three electrolytes. $R_{\mathrm{S}}$ is $0.66 \Omega$, for $\mathrm{KOH}$ solution as compared to much higher values of $2.10 \Omega$ and $3.5 \Omega$ for $\mathrm{LiCl}$ and in $\mathrm{Na}_{2} \mathrm{SO}_{4}$ electrolytes respectively. The charge transfer resistance $\left(R_{\mathrm{CT}}\right)$ values are seen to increase in the same trend. The EIS results also confirms that $\mathrm{K}^{+}$ions have the highest molar conductivity as compared to that of $\mathrm{Li}^{+}$and $\mathrm{Na}^{+}$ions, thus resulting in the smallest $R_{\mathrm{S}}$ and $R_{\mathrm{CT}}$ values.

Fig. 3(b) represents Bode plot for the AC in different electrolytes. It can be seen that in $6.0 \mathrm{M} \mathrm{KOH}$ electrolyte compared to other electrolytes gives the fastest response time demonstrating a phase angle of $-83^{\circ}$ which is close to $-90^{\circ}$ for ideal capacitors at lower frequency. Overall, the obtained results and analysis show good capacitive property of the AC in $6.0 \mathrm{M} \mathrm{KOH}$ electrolyte for supercapacitors.

\section{Conclusion}

Cyclic voltammetry, galvanostatic charge/discharge and electrochemical impedance spectroscopy have been used to compare the electrochemical behaviors for the supercapacitors electrode based on the mesoporous $\mathrm{AC}$ material in $6.0 \mathrm{M} \mathrm{KOH}$, 1.0 $\mathrm{M} \mathrm{Na}_{2} \mathrm{SO}_{4}$ and $6.0 \mathrm{M} \mathrm{LiCl}$ electrolyte solutions. AC electrode in $6.0 \mathrm{M} \mathrm{KOH}$ exhibited excellent electrochemical storage properties including a highest specific capacitance of $124 \mathrm{~F} \mathrm{~g}^{-1}$ at $0.5 \mathrm{~A} \mathrm{~g}^{-1}$. The charge/discharge efficiency of electrode at different current densities of $6 \mathrm{M} \mathrm{KOH}$ electrolyte is higher than both 1.0 $\mathrm{M} \mathrm{Na}_{2} \mathrm{SO}_{4}$ and $6.0 \mathrm{M} \mathrm{LiCl}$ electrolytes and it's close to $100 \%$. The smallest $R_{\mathrm{S}}$ is obtained for the $6.0 \mathrm{M} \mathrm{KOH}$ electrolyte $(0.66 \Omega)$. These results suggest and confirm that $6.0 \mathrm{M} \mathrm{KOH}$ is the ideal aqueous electrolyte and concentration for AC based electrode materials.

\section{Acknowledgements}

This work is based on the research supported by the South African Research Chairs Initiative of the Department of Science 
and Technology and National Research Foundation of South Africa (Grant No. 97994). Any opinion, finding and conclusion or recommendation expressed in this material is that of the author(s) and the NRF does not accept any liability in this regard. F. Barzegar and D. Y. Momodu acknowledge financial support from the University of Pretoria and the NRF while A. Bello acknowledge the University of Pretoria's financial support for their postdoctoral fellowships.

\section{References}

1 R. Kötz and M. Carlen, Electrochim. Acta, 2000, 45, 24832498.

2 B. Conway, J. Electrochem. Soc., 1991, 138, 1539-1548.

3 J. P. Zheng, J. Electrochem. Soc., 1997, 144, 2417-2420.

4 B. E. Conway, Electrochemical Supercapacitors: Scientific Fundamentals and Technological Applications, Kluwer Academic/Plenum, New York, 1999.

5 F. Béguin, V. Presser, A. Balducci and E. Frackowiak, Adv. Mater., 2014, 26, 2219-2251.

6 B. E. Conway, V. Birss and J. Wojtowicz, J. Power Sources, 1997, 66, 1-14.

7 L. L. Zhang and X. S. Zhao, Chem. Soc. Rev., 2009, 38, 25202531.

8 A. G. Pandolfo and A. F. Hollenkamp, J. Power Sources, 2006, 157, 11-27.

9 E. Frackowiak and F. Béguin, Carbon, 2001, 39, 937-950.

10 T. E. Rufford, D. Hulicova-Jurcakova, E. Fiset, Z. Zhu and G. Q. Lu, Electrochem. Commun., 2009, 11, 974-977.

11 W. Li, D. Chen, Z. Li, Y. Shi, Y. Wan, J. Huang, J. Yang, D. Zhao and Z. Jiang, Electrochem. Commun., 2007, 9, 569573.

12 D.-W. Wang, F. Li, M. Liu, G. Q. Lu and H.-M. Cheng, Angew. Chem., Int. Ed., 2008, 47, 373-376.

13 A. Bello, F. Barzegar, D. Momodu, F. Taghizadeh, M. Fabiane, J. Dangbegnon and N. Manyala, RSC Adv., 2014, 4, 39066-39072.

14 X. Zhang, X. Wang, L. Jiang, H. Wu, C. Wu and J. Su, J. Power Sources, 2012, 216, 290-296.

15 C. Lin, J. Electrochem. Soc., 1999, 146, 3639-3643.

16 C. Vix-Guterl, E. Frackowiak, K. Jurewicz, M. Friebe, J. Parmentier and F. Béguin, Carbon, 2005, 43, 1293-1302.
17 C. Zhong, Y. Deng, W. Hu, J. Qiao, L. Zhang and J. Zhang, Chem. Soc. Rev., 2015, 44, 7484-7539.

18 L. Zhang, F. Zhang, X. Yang, G. Long, Y. Wu, T. Zhang, K. Leng, Y. Huang, Y. Ma, A. Yu and Y. Chen, Sci. Rep., 2013, 3, 1408.

19 T. E. Rufford, D. Hulicova-Jurcakova, Z. Zhu and G. Q. Lu, Electrochem. Commun., 2008, 10, 1594-1597.

20 T. A. Centeno, M. Sevilla, A. B. Fuertes and F. Stoeckli, Carbon, 2005, 43, 3012-3015.

21 M. Inagaki, H. Konno and O. Tanaike, J. Power Sources, 2010, 195, 7880-7903.

22 M. Zhi, F. Yang, F. Meng, M. Li, A. Manivannan and N. Wu, ACS Sustainable Chem. Eng., 2014, 2, 1592-1598.

23 M. Zhi, C. Xiang, J. Li, M. Li and N. Wu, Nanoscale, 2012, 5, 72-88.

24 C. Largeot, C. Portet, J. Chmiola, P.-L. Taberna, Y. Gogotsi and P. Simon, J. Am. Chem. Soc., 2008, 130, 2730-2731.

25 P. Simon and Y. Gogotsi, Nat. Mater., 2008, 7, 845-854.

26 P. Hapiot and C. Lagrost, Chem. Rev., 2008, 108, 2238-2264.

27 A. Bello, F. Barzegar, D. Momodu, J. Dangbegnon, F. Taghizadeh and N. Manyala, Electrochim. Acta, 2015, 151, 386-392.

28 Q. T. Qu, B. Wang, L. C. Yang, Y. Shi, S. Tian and Y. P. Wu, Electrochem. Commun., 2008, 10, 1652-1655.

29 J. Zhu, Y. Xu, J. Wang, J. Lin, X. Sun and S. Mao, Phys. Chem. Chem. Phys., 2015, 17, 28666-28673.

30 L. Eliad, G. Salitra, A. Soffer and D. Aurbach, J. Phys. Chem. B, 2001, 105, 6880-6887.

31 F. Barzegar, A. Bello, O. O. Fashedemi, J. K. Dangbegnon, D. Y. Momodu, F. Taghizadeh and N. Manyala, Electrochim. Acta, 2015, 180, 442-450.

32 J. Wang, R. Ma, Z. Zhou, G. Liu and Q. Liu, Sci. Rep., 2015, 5, 9304.

33 W. Zhang, C. Ma, J. Fang, J. Cheng, X. Zhang, S. Dong and L. Zhang, RSC Adv., 2013, 3, 2483-2490.

34 R. N. Reddy and R. G. Reddy, J. Power Sources, 2003, 124, 330-337.

35 I. Waluyo, C. Huang, D. Nordlund, U. Bergmann, T. M. Weiss, L. G. M. Pettersson and A. Nilsson, J. Chem. Phys., 2011, 134, 064513.

36 P. Yates, Chemical Calculations: Mathematics for Chemistry, CRC Press, 2nd edn, 2007. 